\title{
Prediction of myocardial tissue loss by quantitative densitometric myocardial blush parameters following ST-elevation myocardial infarction
}

\author{
V Sasi ${ }^{1}$, H Gavallér ${ }^{1,3}$, A Kalapos ${ }^{1}$, P Domsik ${ }^{1}$, FT Nagy ${ }^{1}$, T Ungi ${ }^{2}$, I Ungi ${ }^{1}$, \\ T Forster ${ }^{1}$, A Nemes ${ }^{1}$ \\ ${ }^{1}$ Division of Invasive Cardiology, Department of Cardiology, Medical Faculty, \\ Albert Szent-Györgyi Clinical Center, University of Szeged, Szeged, Hungary \\ ${ }^{2}$ Queen's University, School of Computing, Kingston, ON, Canada \\ ${ }^{3}$ Diagnoscan Magyarország Ltd., Szeged, Hungary
}

Received: April 29, 2014

Accepted after revision: March 8, 2015

\begin{abstract}
Tissue level myocardial perfusion is one of the most important prognostic factors after successful recanalisation of the occluded coronary artery in patients suffering acute ST elevation myocardial infarction (STEMI). The primary objective of the present study was to examine the relationship between videodensitometric myocardial perfusion parameters as assessed on coronary angiograms directly following successful recanalization therapy and magnetic resonance imaging (MRI)-derived myocardial tissue loss late after STEMI. The study comprised 29 STEMI patients. Videodensitometric parameter $\mathrm{G}_{\max } / \mathrm{T}_{\max }$ was calculated to characterize myocardial perfusion, derived from the plateau of grey-level intensity $\left(\mathrm{G}_{\max }\right)$, divided by the time-to-peak intensity $\left(\mathrm{T}_{\max }\right)$. Myocardial loss index (MLI) was assessed by cardiac MRI following $376 \pm 254$ days after PCI. Results: Significant correlations could be demonstrated between MLI and $\mathrm{G}_{\max }(r=0.36, p=0.05)$ and $\mathrm{G}_{\max } / \mathrm{T}_{\max }(r=0.40, p=0.03)$ using vessel masking. Using receiver operating characteristic curve analysis, $\mathrm{G}_{\max } / \mathrm{T}_{\max }<2.17$ predicted best MLI $=0.3,0.4,0.5$ and 0.6 with good sensitivity and specificity data, while $\mathrm{G}_{\max } / \mathrm{T}_{\max }<3.25$ proved to have a prognostic role in the prediction of MLI = 0.7. Conclusions: Selective myocardial tissue level perfusion quantitative measurement method is feasible and can serve as a good predictor of myocardial tissue loss following STEMI and revascularization therapy.
\end{abstract}

Keywords: myocardial infarction, blush, densitometry, coronary angiography, prediction

The primary objective of treatment in acute ST elevation myocardial infarction (STEMI) is to restore normal blood flow in the infarction-related epicardial coronary artery and to obtain the best possible reperfusion of the myocardium at risk. In daily practice percutaneous primary coronary intervention (PCI) is the preferred method of choice (15). Assessment of myocardial perfusion on coronary angiograms is routinely performed by visual estimation. In clinical circumstances, two visual grading scales proved to be informative in assessing perfusion of the infarction-related myocardium: the Myocardial Blush Grade (MBG) (18) and TIMI Myocardial Perfusion Grade (TMPG) (3). Both grades have four levels: grades 0 and 1 representing no or minimal contrast signal in the infarction-related myocardium, while grades 2 and 3 representing impaired and normal states. The inter- and intraobserver

Corresponding author: Attila Nemes, MD, PhD, DSc, FESC

2nd Department of Medicine and Cardiology Center, Medical Faculty

Albert Szent-Györgyi Clinical Center, University of Szeged

Semmelweis utca 6, P.O. Box 427, H-6725 Szeged, Hungary

Phone: +36-62-545220; Fax: +36-62-544568; E-mail: nemes.attila@med.u-szeged.hu 
variabilities associated with subjective angiographic perfusion assessments are known limitations of these visual grading tools. Korosoglou et al. have found that computerized videodensitometric method for the evaluation of quantitative MBG is highly predictive for functional recovery in patients after STEMI (6).

Optimally, it would be important to develop an operator-independent and quantitative way for myocardial tissue-level perfusion assessment based on X-ray coronary angiograms to be used in clinical circumstances. Despite promising results, none of these methods has yet been shifted into the clinical practice or became a standard endpoint of clinical trials in place of the four-graded visual assessment. Our group presented a method for computerized densitometric perfusion analysis on digital subtraction coronary angiograms (DSA) in STEMI patients (16). The primary objective of the present study was to examine the relationship between videodensitometric myocardial perfusion parameters as assessed on coronary angiograms directly following successful recanalization therapy and magnetic resonance imaging (MRI)-derived myocardial lost tissue late after STEMI.

\section{Materials and Methods}

\section{Study population}

A registry has been created to collect all the data of patients undergone densitometric myocardial blush assessment. The present study comprised 29 consecutive patients with STEMI, who had undergone PCI. The following inclusion criteria were used during enrollment of patients:

(1) acute ST elevation in contiguous leads on 12-lead ECG

(2) pain-to-balloon time $<12 \mathrm{~h}$

(3) total occlusion of the proximal segment of one of the three main coronary arteries, and

(4) capability of the patient to cooperate with the recording of the coronary angiograms.

Patients who were unconscious or showed signs of cardiogenic shock or had visible collateral circulation in the infarction-related myocardial region were excluded from the study. Informed consent was obtained from each patient and the study protocol conformed to the ethical guidelines of the 1975 Declaration of Helsinki, as reflected in a prior approval by the institution's human research committee.

\section{Percutaneous coronary intervention}

All patients received acetyl-salicylic acid $(500 \mathrm{mg})$, clopidogrel $(600 \mathrm{mg})$ and at least 5000 IU of unfractionated Na-heparine prior to PCI. Performance of PCI followed available guidelines (13). At the end of procedure prior to last coronary blush angiography $200 \mu \mathrm{g}$ ic. nitroglycerin was administered (if haemodynamic status was stable).

\section{Technical features of coronary angiography}

Angiograms for videodensitometric analysis were recorded and phase-matched DSA was performed in all cases $(14,16)$. This required the following criteria:

(1) motion of the patient or the catheterization table should be avoided during angiography

(2) patient should hold their breath during the period of the recording

(3) one contrast-free heart cycle should be recorded before injection of contrast material

(4) careful adjustment of field of view to contain the entire supplied area of the vessel of interest. 
Projections were chosen to minimize the superpositioning of non-infarction-related myocardium and edge of the diaphragm, which could cause motion artifacts on DSA images. Left anterior descending coronary artery (LAD) and left circumflex artery (LCX) territory were recorded in lateral view (LAO $90^{\circ}$ ), while territory supplied by the right coronary artery (RCA) was recorded in LAO $15^{\circ}$. The same nonionic contrast material (Visipaque, $320 \mathrm{mg} /$ $\mathrm{ml}$ iodine) was used for all angiograms injected by an injector; contrast quantity was $6 \mathrm{ml}$; injection rate proved to be $3 \mathrm{ml} / \mathrm{s}$. Angiograms were recorded on an Innova 2000 system (GE Healthcare, Chalfont St. Giles, Buckinghamshire, UK). Images were stored in $512 \times 512$ size, 8-bit, grayscale, uncompressed format.

\section{Videodensitometric analysis}

Phase-matched DSA angiograms were recorded on the same way in each patient with constant quantity contrast delivered, brightness, and stabilized acquisition parameters of the X-ray imaging system (Fig. 1) (16). The computerized method for myocardial perfusion assessment was based on the analysis of time-density curves (TDCs) measured over the infarction-related myocardial region of interest (ROI). Polygonal-shaped ROIs were selected by an experienced interventional cardiologist and covered the entire myocardial area at risk. Vesselness probability maps were calculated for each image frame according to Frangi et al. (2). TDCs were calculated as average pixel value in the ROI, excluding pixels having a vesselness probability value $>0.08$. Frequencies higher than $0.6 \mathrm{~Hz}$ have been removed from the TDC to eliminate artifacts from cyclic heart contractions, and noise in image acquisition. Myocardial perfusion has a single-wave density signal around $0.1 \mathrm{~Hz}$; therefore it is still present on the filtered curve. Frequency filtering was performed using the Matlab 7.0 mathematical software. Maximal density of the TDC $\left(\mathrm{G}_{\max }\right.$, in relative pixel unit, rpu) and time to reach maximum density $\left(\mathrm{T}_{\max }\right.$ in $\mathrm{sec}$ ) were measured on the filtered curve (16). Myocardial perfusion was characterized by $\mathrm{G}_{\max } / \mathrm{T}_{\max }$.

\section{Cardiac magnetic resonance imaging analysis}

For evaluation of late LV (left ventricular) myocardial infarction size, cardiac MRI was performed $376 \pm 254$ days after PCI using a 1.5 Tesla GE Signa $^{\circledR}$ EXCITE $^{\circledR}$ MRI (GE Healthcare, Waukesha, Wisconsin, USA) equipment with a cardiac software package (Fig. 2). Patients were positioned in the supine position, with a cardiac 8-element phased-array coil placed over the thorax. Repeated breath-holds and electrocardiographic gating were applied to minimize the influence of cardiac and respiratory motion on data collection. 2D FIESTA sequence was performed, imaging parameters were as follows: repetition time, $3.6 \mathrm{~ms}$; echo time, $1.6 \mathrm{~ms}$; flip angle, $50^{\circ}$; field of view, $43 \times 38.9 \mathrm{~cm}$; matrix, $224 \times 224$. To cover the entire LV 8 to 12 consecutive slices of $8 \mathrm{~mm}$ in the short axis view were planned on the 4 chambers (gap, $0 \mathrm{~mm}$ ). Papillary muscles were considered as part of the LV cavity.

\section{Myocardial loss index}

Late gadolinium enhancement MRI images were used for assessing infarcted myocardial regions. A single bolus dose of $0.15 \mathrm{mmol} / \mathrm{kg}$ of gadolinium DTPA was used in all cases, and late enhancement was considered present only if confirmed on both short-axis and matching long-axis myocardial locations. In order to have numerous values for lost myocardial tissue, coronary angiograms were analyzed and the location of occlusion was pinpointed and according to SYNTAX coronary segment analysis the supplied myocardial area was defined according to the recommendations of the American Society of Echocardiography (7). After 
the number of supplied segments was calculated, each segment was analyzed on late gadolinium enhancement MRI and the transmural loss was calculated in each segment according to MRI data obtained of each segment. $0 \%$ loss of tissue meant $1,25 \%$ loss equaled $0.75,50 \%$ equaled $0.5,75 \%$ meant $0.25,100 \%$ translated to 0 . This way the viable tissue was defined for each supplied segment and the sum of each supplied segment analysis was divided by the number of supplied segment distal to the occlusion. The dividend was defined as the myocardial loss index (MLI) (lower MLI means higher myocardial tissue loss).

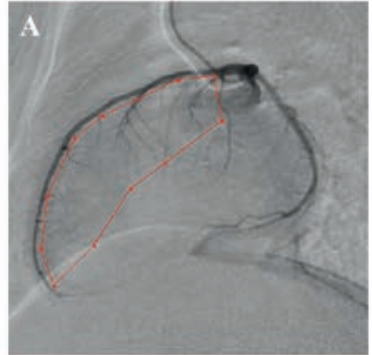

D

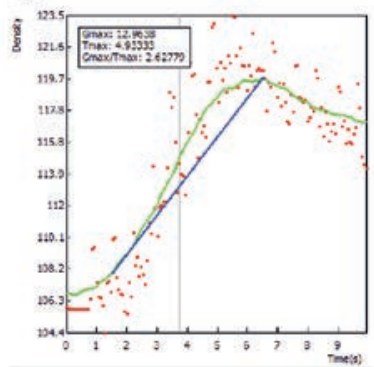

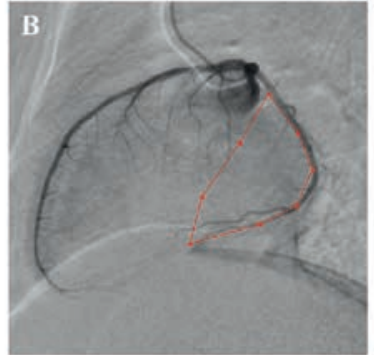

$\mathbf{E}$

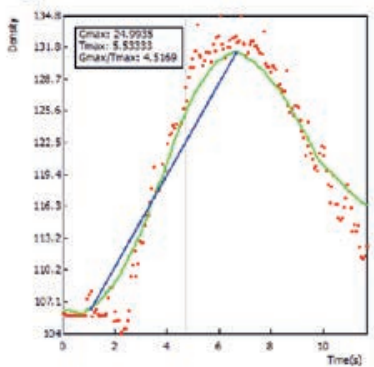

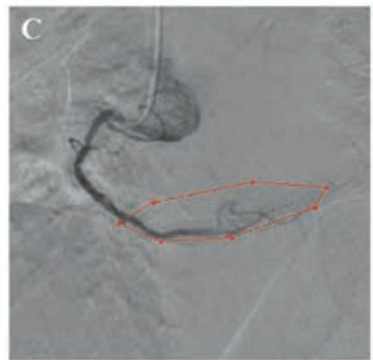

F

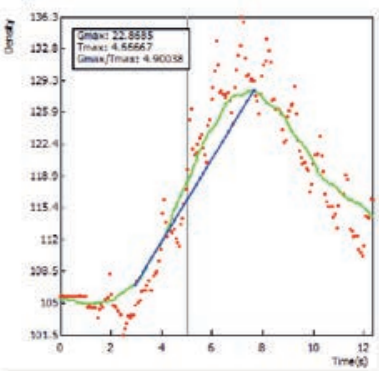

Fig. 1. Post-angioplastic digital subtraction angiographic images of the left anterior descending coronary artery (LAD, Panel A), left circumflex coronary artery (CX, Panel B) and right coronary artery (RC, Panel C) of a patient with anterior ST elevation myocardial infarction are presented on the top panels.

Time-density curves related to the above mentioned images are presented on lower panels (D, E, F) together with maximum density of the time-density curve $\left(\mathrm{G}_{\max }\right)$, the time to reach maximum density $\left(\mathrm{T}_{\max }\right)$ and their ratio $\left(\mathrm{G}_{\max } / \mathrm{T}_{\max }\right)$. While LAD-related videodensitometric perfusion was found to be impaired in this case $\left(\mathrm{G}_{\max } / \mathrm{T}_{\max }=2.63\right)$ (Panels $A$ and $\left.\mathrm{D}\right), \mathrm{CX}$ - and $\mathrm{RC}$-related $\mathrm{G}_{\max } / \mathrm{T}_{\max }$ proved to be normal (4.52 and 4.90, respectively) (Panels B-E and C-F)

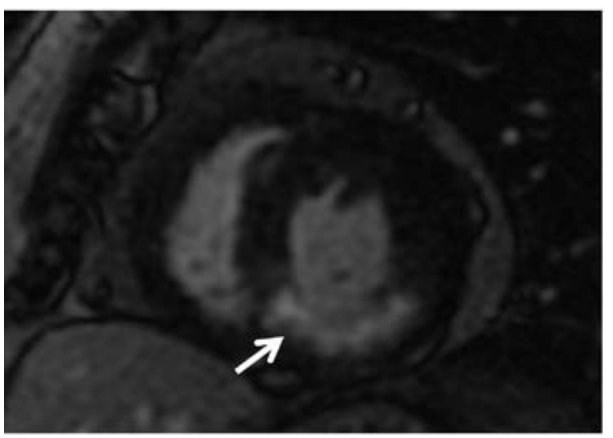

Fig. 2. A magnetic resonance cross-sectional image of a patient with myocardial infarction is presented (see white arrow) 
Statistical analysis

All statistical tests were performed with MedCalc software (MedCalc, Mariakerke, Belgium). A value of $p<0.05$ was considered to be statistically significant. Correlation of $\mathrm{G}_{\max }$ and $\mathrm{G}_{\max } /$ $\mathrm{T}_{\max }$ with clinical parameters was assessed by a Pearson's correlation coefficient. To establish the predictive power of $\mathrm{G}_{\max } / \mathrm{T}_{\max }$ receiver operating characteristic (ROC) curves were constructed and the area under the curves was reported with sensitivity and specificity values.

\section{Results}

\section{Clinical and demographic data}

Clinical data of the patient population are summarized in Table I. The most important baseline laboratory findings and medications applied are presented in Table II.

Table I. Baseline characteristics and clinical data of patients

\begin{tabular}{|l|c|}
\hline & Data \\
\hline Number of patients & 29 \\
\hline Age (years) & $59.1 \pm 10.9$ \\
\hline Male gender (\%) & $21(72)$ \\
\hline Diabetes mellitus (\%) & $7(24)$ \\
\hline Hypertension (\%) & $20(69)$ \\
\hline Hypercholesterolaemia (\%) & $18(62)$ \\
\hline Smoking (\%) & $19(66)$ \\
\hline Previous myocardial infarction (\%) & $3(10)$ \\
\hline $\begin{array}{l}\text { Family history of coronary artery } \\
\text { disease (\%) }\end{array}$ & $15(52)$ \\
\hline Weight $(\mathrm{kg})$ & $85.1 \pm 20.2$ \\
\hline Height $(\mathrm{cm})$ & $169.8 \pm 10.1$ \\
\hline Body mass index $\left(\mathrm{kg} / \mathrm{m}^{2}\right)$ & $29.2 \pm 5.6$ \\
\hline
\end{tabular}

Table II. The most important laboratory findings and medications taken at index procedure

\begin{tabular}{|l|c|}
\hline & Data \\
\hline Medicines & \\
\hline $\begin{array}{l}\text { Acethyl-salicylic acid / Clopidogrel } \\
(\%)\end{array}$ & $4(14)$ \\
\hline ACE inhibitor / ARB (\%) & $8(28)$ \\
\hline Beta-blocker (\%) & $2(7)$ \\
\hline Statin (\%) & $2(7)$ \\
\hline Nitrate (\%) & $2(7)$ \\
\hline Laboratory findings & \\
\hline Total cholesterol level (mmol/1) & $5.00 \pm 1.35$ \\
\hline LDL cholesterol level (mmol/1) & $3.08 \pm 1.13$ \\
\hline HDL cholesterol level (mmol/1) & $1.22 \pm 0.44$ \\
\hline Triglycerid level (mmol/l) & $1.54 \pm 1.10$ \\
\hline Blood urea nitrogen (mmol/1) & $7.11 \pm 2.61$ \\
\hline Creatinine (umol/l) & $76.83 \pm 23.71$ \\
\hline Haematocrit (\%) & $40.00 \pm 4.40$ \\
\hline Haemoglobin (g/l) & $134.38 \pm 12.53$ \\
\hline
\end{tabular}

Abbreviations: $\mathrm{ACE}=$ angiotensine-converting enzyme, $\mathrm{ARB}=$ angiotensine receptor blocker, $\mathrm{HDL}=$ high density lipoprotein, $\mathrm{LDL}=$ low density lipoprotein

\section{Coronary angiographic, videodensitometric and MRI data}

Distribution of STEMI-related coronary arteries is demonstrated in Table III. All patients eligible for the study had undergone successful revascularization achieving TIMI 3 flow with residual stenosis less than 30\%. Multivessel disease (MVD) was present in 14 cases (48\%), where significant non-infarction-related lesions were treated $8 \pm 1$ weeks after the index procedure. Bare metal stents were implanted at the index procedure in all cases. Clinically driven repeated revascularization (target lesion revascularization) was performed with drugeluting stents in 3 cases (10\%) during the follow-up. Myocardial blush parameters as assessed by videodensitometry on the closing coronary angiograms following PCI with vs. without vessel masking are presented in Table III. Mean MRI-derived MLI proved to be $0.65 \pm 0.23$. 
Table III. Results of coronary angiography and densitometric measurements

\begin{tabular}{|l|c|}
\hline & Data \\
\hline Coronary angiography & \\
\hline Significant one-vessel disease (\%) & $15(52)$ \\
\hline Significant two-vessel disease (\%) & $9(31)$ \\
\hline Significant three-vessel disease (\%) & $5(17)$ \\
\hline Place of infarction-related total occlusion & \\
\hline Left anterior descending coronary artery (\%) & $8(28)$ \\
\hline Left circumflex coronary artery (\%) & $5(17)$ \\
\hline Right coronary artery (\%) & $16(55)$ \\
\hline Results of densitometric measurements & $13.56 \pm 6.51$ \\
\hline $\mathrm{G}_{\max }$ (without vessel masking) (rpu) & $4.84 \pm 1.39$ \\
\hline $\mathrm{T}_{\max }$ (without vessel masking) (sec) & $2.86 \pm 1.27$ \\
\hline $\mathrm{G}_{\max } / \mathrm{T}_{\text {max }}$ (without vessel masking) (rpu/sec) & $11.53 \pm 5.64$ \\
\hline $\mathrm{G}_{\max }($ with vessel masking) (rpu) & $4.37 \pm 1.11$ \\
\hline $\mathrm{T}_{\max }$ (with vessel masking) (sec) & $2.64 \pm 1.12$ \\
\hline $\mathrm{G}_{\max } / \mathrm{T}_{\text {max }}$ (with vessel masking) (rpu/sec) & $5.86 \pm 1.33$ \\
\hline Number of regions supplied by the infarction-related artery & \\
\hline
\end{tabular}

Abbreviations: $\mathrm{G}_{\max }=$ maximum density of time-density curve,

$\mathrm{T}_{\max }=$ time to reach maximum density of time-density curve, $\mathrm{rpu}=$ relative pixel unit

\section{Correlations}

Significant correlations could be demonstrated between MLI and $\mathrm{G}_{\max }(r=0.36, p=0.05)$ and $\mathrm{G}_{\max } / \mathrm{T}_{\max }(r=0.40, p=0.03)$ using vessel masking (Fig. 3). Similar correlations were found for the 16 patients with same occlusion site (RCA), as a homogeneous group $(r=0.32, p=$ 0.05 and $r=0.38, p=0.05$, respectively).
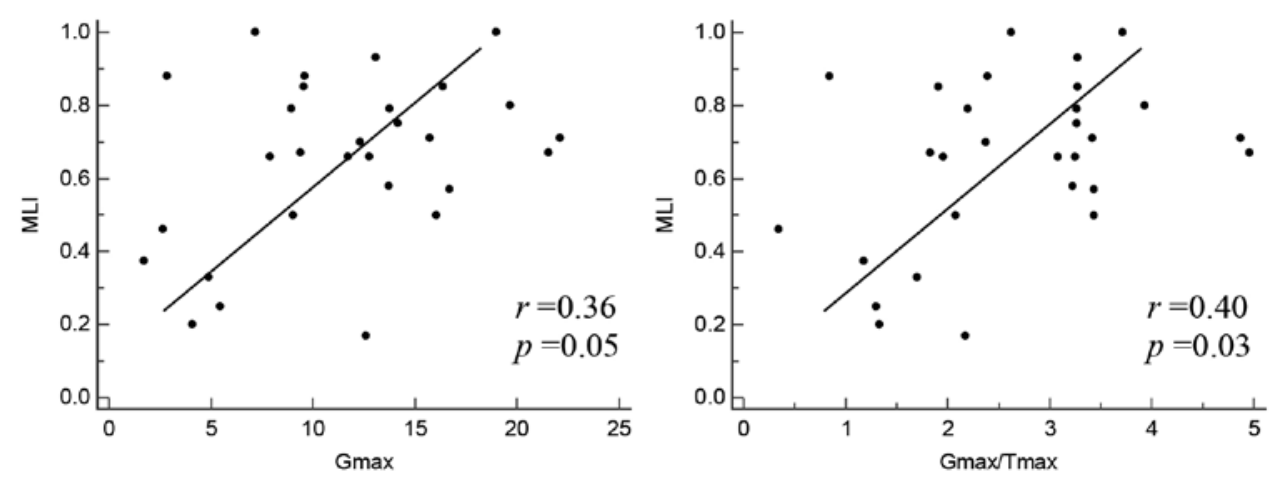

Fig. 3. Significant correlations could be demonstrated between MLI and $\mathrm{G}_{\max }$ and $\mathrm{G}_{\max } / \mathrm{T}_{\max }$ 
ROC analysis

Using ROC analysis, $\mathrm{G}_{\max } / \mathrm{T}_{\max }<2.17$ predicted best $\mathrm{MLI} \leq 0.3,0.4,0.5$ and 0.6 with good sensitivity and specificity data, while $\mathrm{G}_{\max } / \mathrm{T}_{\max }<3.25$ proved to have a prognostic role in the prediction of MLI $\leq 0.7$ (Fig. 4).
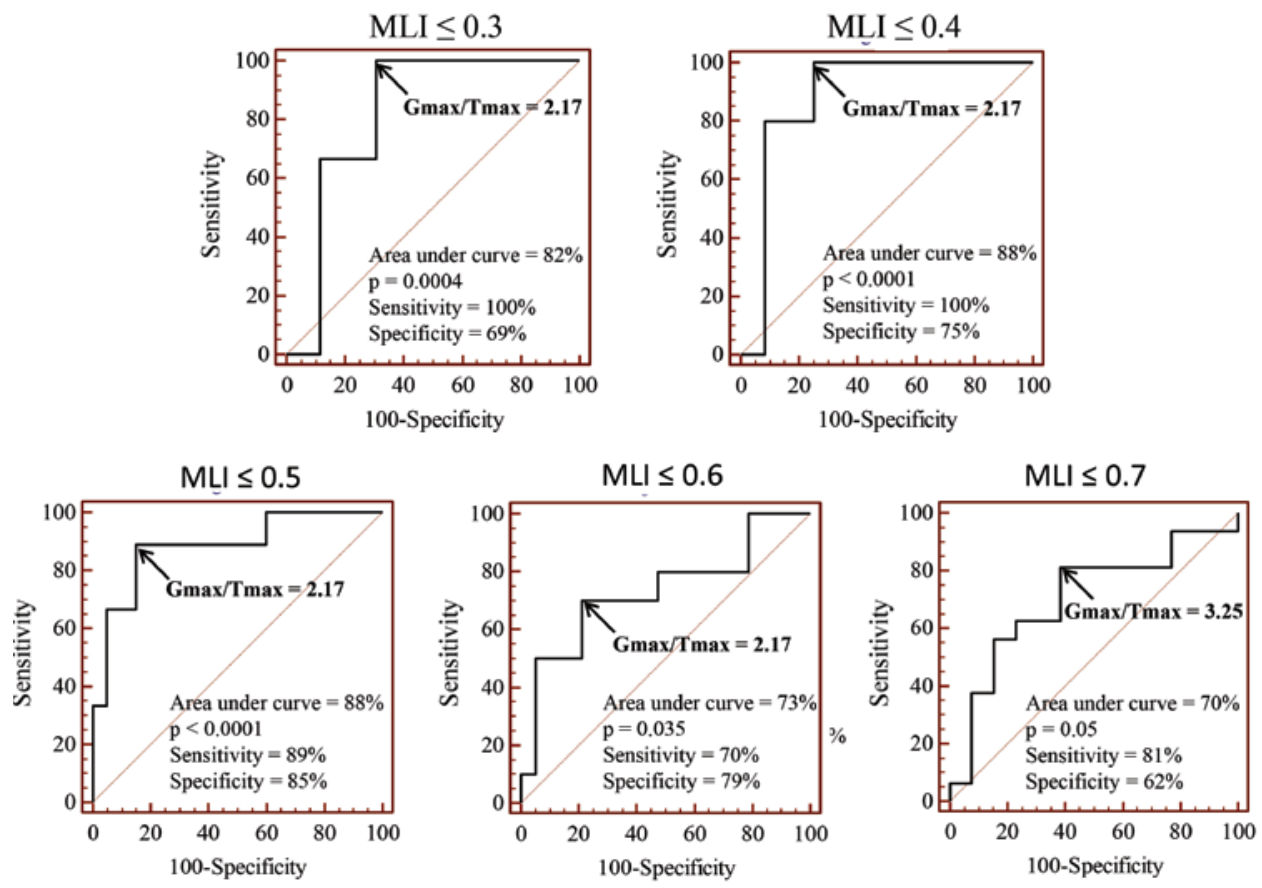

Fig. 4. Receiver operating characteristic analysis confirmed that $\mathrm{G}_{\max } / \mathrm{T}_{\max }=2.17$ predicted best myocardial loss index $(\mathrm{MLI}) \leq 0.3, \leq 0.4, \leq 0.5$ and $\leq 0.6$ with good sensitivity and specificity data, while $\mathrm{G}_{\max } / \mathrm{T}_{\max }=3.25$ proved to have a prognostic role in the prediction of $\mathrm{MLI} \leq 0.7$

\section{Discussion}

Traditionally, normalized epicardial blood flow means success after recanalization of the occluded artery in patients with STEMI. TIMI grade 3 epicardial coronary blood flow could be achieved in more than $90 \%$ in experienced invasive cardiology centers. However, TIMI grade 3 flow is not equivalent to good myocardial tissue level perfusion thus long-term good clinical outcome and decreased mortality could be obtained, which has been well described in 1990s by different imaging modality studies, such as MRI (19) and radionuclide studies (5). Poor microcirculatory perfusion after primary PCI could result in larger enzymatic infarction size, lower residual LV-EF, higher mortality, and higher incidence of major adverse cardiac events in a long-term follow-up (4). The opportunities to assess myocardial perfusion in the catheterization laboratory are limited despite the fact that different grading scales are available in clinical practice including MBG and TMPG assessment. Hoffmann et al. demonstrated that MBG early and late after primary coronary angioplasty for acute myocardial infarction had a prognostic impact on LV function (20). Moreover, MBG is a good predictor of infarction size in STEMI patients treated with PCI (21). Videodensitometric analysis of myocardial perfusion theoretically could overcome problems related to grading scales (for 
instance their categorical nature), but its prognostic value to predict myocardial tissue loss has never been assessed. Therefore we decided to examine the relationship between myocardial perfusion parameters as assessed after PCI in STEMI patients by densitometry on coronary angiograms and late MRI-derived characteristics of myocardial damage. Regarding to our results low densitometry-derived $\mathrm{G}_{\max } / \mathrm{T}_{\max }$ seems to have a prognostic role in the prediction of myocardial tissue loss at 1-year follow-up. Moreover, significant correlation could be detected between extent of myocardial infarction as expressed by MLI and densitometric $\mathrm{G}_{\max } / \mathrm{T}_{\max }$ myocardial blush parameters.

The usefulness of the presented videodensitometric method has already been demonstrated in clinical circumstances $(8-12,14,16-17)$. It has been validated against thermodilution-derived coronary flow reserve (CFR) assessments (9) and corrected TIMI frame count (cTFC) calculations (10). Relationship could be demonstrated between early indicators of myocardial damage and myocardial blush parameters in an early study (16). Moreover, vessel masking during densitometric analysis proved to be a method of choice to improve sensitivity in the detection of myocardial damage (17). Altered densitometric myocardial blush parameters were found in patients with hypertension (11) and aortic valve stenosis (8) without overt coronary artery disease and in subjects with hypertrophic cardiomyopathy following alcohol septal ablation (12).

\section{Limitation section}

Despite promising results several limiting factors could affect our results including

- Computer-assisted myocardium selective densitometric method is a continuously developing clinical imaging tool. Several technical problems still exist including static ROI definition. Too large ROI could be associated with inhomogeneous distribution of the contrast, while cycle motion of the heart could be problematic for too small ROI.

- Forty-eight percent of patients had MVD. It is important to be considered that collateral systems associated with MVD could affect myocardial perfusion assessments, as well.

- The software used is not available freely, therefore, comparison with other techniques is not possible at this moment.

- The effect of different drugs and other disorders on study outcome was not evaluated in this study.

- Low number of patients was evaluated. Myocardial blush parameters measured for different infarction-related coronary arteries were not calculated separately.

\section{Conclusions}

Selective myocardial perfusion quantitative measurement $\left(\mathrm{G}_{\max } / \mathrm{T}_{\max }\right)$ method is feasible and can serve as a good predictor of myocardial lost tissue level after STEMI and revascularization therapy. 


\section{REFERENCES}

1. Choi KM, Kim RJ, Gubernikoff G, Vargas JD, Parker M, Judd RM: Transmural extent of acute myocardial infarction predicts long-term improvement in contractile function. Circulation 104, 1101-1107 (2001)

2. Frangi AF, Niessen WJ, Vincken KL, Viergever MA: Multiscale vessel enhancement filtering. Lect. Notes Comput. Sci. 1496, 130-137 (1998)

3. Gibson CM, Cannon CP, Murphy SA, Ryan KA, Mesley R, Marble SJ, McCabe CH, Van De Werf F, Braunwald E: Relationship of TIMI myocardial perfusion grade to mortality after administration of thrombolytic drugs. Circulation 101, 125-130 (2000)

4. Henriques JP, Zijlstra F, van't Hof AW, de Boer MJ, Dambrink JH, Gosselink M, Hoorntje JC, Suryapranata H: Angiographic assessment of reperfusion in acute myocardial infarction by myocardial blush grade. Circulation $107,2115-2119$ (2003)

5. Kondo M, Nakano A, Saito D, Shimono Y: Assessment of "microvascular no-reflow phenomenon" using technetium-99m macroaggregated albumin scintigraphy in patients with acute myocardial infarction. J. Am. Coll. Cardiol. 32, 898-903 (1998)

6. Korosoglou G, Haars A, Michael G, Erbacher M, Hardt S, Giannitsis E, Kurz K, Franz-Josef N, Dickhaus H, Katus HA, Kuecherer H: Quantitative evaluation of myocardial blush to assess tissue level reperfusion in patients with acute ST-elevation myocardial infarction: incremental prognostic value compared with visual assessment. Am. Heart J. 153, 612-620 (2007)

7. Lang RM, Bierig M, Devereux RB, Flachskampf FA, Foster E, Pellikka PA, Picard MH, Roman MJ, Seward J, Shanewise JS, Solomon SD, Spencer KT, Sutton MS, Stewart WJ; Chamber Quantification Writing Group; American Society of Echocardiography's Guidelines and Standards Committee; European Association of Echocardiography: Recommendations for chamber quantification: a report from the American Society of Echocardiography's Guidelines and Standards Committee and the Chamber Quantification Writing Group, developed in conjunction with the European Association of Echocardiography, a branch of the European Society of Cardiology. J. Am. Soc. Echocardiogr. 18, 1440-1463 (2005)

8. Nagy FT, Horváth T, Ungi T, Sasi V, Zimmermann Z, Kalapos A, Forster T, Ungi I, Nemes A: Aortic valve stenosis is associated with reduced myocardial perfusion as assessed by videodensitometry in coronary angiograms. Orv. Hetil. 153, 1256-1262 (2012)

9. Nagy FT, Nemes A, Szűcsborus T, Ungi T, Katona A, Sasi V, Zimmermann Z, Kalapos A, Forster T, Ungi I: Validation of videodensitometric myocardial perfusion assessment. Cent. Eur. J. Med. 8, 600-607 (2013)

10. Nagy FT, Sasi V, Ungi T, Zimmermann Z, Ungi I, Kalapos A, Forster T, Nemes A: Correlations between myocardium selective videodensitometric perfusion parameters and corrected TIMI frame count in patients with normal epicardial coronary arteries. Int. J. Cardiol. 155, 498-501 (2012)

11. Nemes A, Kalapos A, Sasi V, Ungi T, Nagy FT, Zimmermann Z, Forster T, Ungi I: Detection of perfusion abnormalities on coronary angiograms in hypertension by myocardium selective densitometric perfusion assessments. Int. J. Cardiol. 157, 428-429 (2012)

12. Nemes A, Kalapos A, Sasi V, Ungi T, Ungi I, Forster T, Sepp R: Videodensitometric time-density curve change after alcohol septal ablation of obstructive hypertrophic cardiomyopathy. Neth. Heart J. 23, 143-144 (2015)

13. Patel MR, Dehmer GJ, Hirshfeld JW, Smith PK, Spertus JA: ACCF/SCAI/STS/AATS/AHA/ASNC 2009 Appropriateness Criteria for Coronary Revascularization: A Report of the American College of Cardiology Foundation Appropriateness Criteria Task Force, Society for Cardiovascular Angiography and Interventions, Society of Thoracic Surgeons, American Association for Thoracic Surgery, American Heart Association, and the American Society of Nuclear Cardiology: Endorsed by the American Society of Echocardiography, the Heart Failure Society of America, and the Society of Cardiovascular Computed Tomography. Circulation 119, 13301352 (2009)

14. Sasi V, Kalapos A, Gavallér H, Domsik P, Ungi T, Zimmermann Z, Nagy FT, Horváth T, Forster T, Nemes A: Relationship between early myocardial reperfusion assessed by videodensitometry and late left ventricular function. Results following invasive treatment of acute myocardial infarction. Orv. Hetil. 155, 187-193 (2014) (in Hungarian)

15. The Task Force on the management of ST-segment elevation acute myocardial infarction of the European Society of Cardiology (ESC), Steg PG, James SK, Atar D, Badano LP, Blömstrom-Lundqvist C, Borger MA, di Mario C, Dickstein K, Ducrocq G, Fernandez-Aviles F, Gershlick AH, Giannuzzi P, Halvorsen S, Huber K, Juni P, Kastrati A, Knuuti J, Lenzen MJ, Mahaffey KW, Valgimigli M, van’t Hof A, Widimsky P, Zahger D: ESC Guidelines for the management of acute myocardial infarction in patients presenting with ST-segment elevation. Eur. Heart J. 33, 2569-2619 (2012) 
16. Ungi T, Ungi I, Jónás Z, Sasi V, Lassó A, Zimmermann Z, Forster T, Palkó A, Nemes A: Myocardium selective densitometric perfusion assessment after acute myocardial infarction. Cardiovasc. Revasc. Med. 10, 49-54 (2009)

17. Ungi T, Zimmermann Z, Balázs E, Lassó A, Ungi I, Forster T, Palkó A, Nemes A: Vessel masking improves densitometric myocardial perfusion assessment. Int. J. Cardiovasc. Imaging 25, 229-236 (2009)

18. van’t Hof AW, Liem A, Suryapranata H, Hoorntje JC, de Boer MJ, Zijlstra F: Angiographic assessment of myocardial reperfusion in patients treated with primary angioplasty for acute myocardial infarction: myocardial blush grade. Zwolle Myocardial Infarction Study Group. Circulation 97, 2302-2306 (1998)

19. Wu KC, Zerhouni EA, Judd RM, Lugo-Olivieri CH, Barouch LA, Schulman SP, Blumenthal RS, Lima JA. Prognostic significance of microvascular obstruction by magnetic resonance imaging in patients with acute myocardial infarction. Circulation 97, 765-772 (1998)

20. Hoffmann R, Haager P, Arning J, Christott P, Radke P, Blindt R, Ortlepp J, Lepper W, Hanrath P. Usefulness of myocardial blush grade early and late after primary coronary angioplasty for acute myocardial infarction in predicting left ventricular function. Am. J. Cardiol. 92, 1015-1019 (2003)

21. Rasoul S, Dambrink JH, Breeman A, Elvan A, van't Hof AW: The relation between myocardial blush grade and myocardial contrast echocardiography: which one is a better predictor of myocardial damage? Neth. Heart J. 18, 25-30 (2010) 